\title{
THE DYNAMICS OF EUROPEAN PERIPHERY
}

\author{
Lishchynskyy Ihor ${ }^{1}$, Lyzun Mariia², Vitalina Kuryliak ${ }^{3}$, Yevhen Savelyev ${ }^{4}$ \\ ${ }^{1}$ Assoc. Prof. PhD. Ternopil National Economic University, Ternopil, Ukraine. \\ Phone number+380958339576.E-mail address lischynigor@ukr.net \\ ${ }^{2}$ Assoc. Prof. Dr. Ternopil National Economic University, Ternopil, Ukraine. \\ Phone number+380976716100.E-mail address mlysun@ukr.net \\ ${ }^{3}$ Prof. Dr. Ternopil National Economic University, Ternopil, Ukraine. \\ E-mail address: ternopil2000@yahoo.com \\ ${ }^{4}$ Prof. Dr. Ternopil National Economic University, Ternopil, Ukraine. \\ E-mail address yev.savelyev@gmail.com
}

Received 3110 2019; Accepted 20122019

The paper investigates the economic dynamics of peripheral regions in Europe. There is no consensus among researchers and practitioners concerning the long-term trends of spatial disproportions among European regions. Though there is obvious evidence of inter-national convergence in the EU, the inter-regional convergence is still a challenge. Thus, territorial cohesion and balanced regional development become the main tasks of the EU Territorial Agenda.

The main purpose of the paper is to inspect the ability of peripheral regions to demonstrate the tendency for anticipatory growth. The authors investigate the theoretical backgrounds of peripheral emergence, make a review of the empirical researches on regional peripheralization in Europe and analyze the quantitative indicators of the European periphery's dynamics. The conclusion is made that there is a strong tendency toward the emergence of new growth poles to the east of "Blue Banana", the traditional European economic spine.

Keywords: periphery, core, economic geography, regional economics, spatial disproportion, territorial policy, Europe.

JEL Codes: R11, R58, Q01.

\section{Introduction}

The conceptual background of the uneven regional development and, accordingly, the emergence of peripheral territories is rather diverse. The problems of peripheralization are addressed in almost all models of economic geography. Due to the size constraints, in this paper we would not consider "static" concepts of firm placement and agglomeration formation that also reveal the reasons for the economic backwardness of individual territories. Instead, we will focus on more "dynamic" models of inter-regional translation of local growth and development. The neoclassical approach focuses on the long-term aspects of interregional mobility of production factors and the relationship of the latter with technological change.

Copyright (C) 2019 The Authors. Published by Vytautas Magnus University. This is an open-access article distributed under the terms of the Creative Commons Attribution-NonCommercial 4.0 (CC BY-NC 4.0) license, which permits unrestricted use, distribution, and reproduction in any medium, provided the original author and source are credited. The material cannot be used for commercial purposes. 
According to the neoclassicists, in the long run, the mechanism of self-regulation leads to overcoming regional differences and achieving equilibrium, and consequently, the lag of the peripheral territories will eventually be smoothed out in accordance with one of the types of absolute $(\sigma, \beta)$, conditional or club convergence. In earlier exogenous theory, regional growth, in the long run, was only possible due to technological changes (McCann, 2013). The later endogenous version emphasizes to a greater extent the effects of interregional "knowledge spillovers" and the development of regional human capital (Lucas, 1988; McCombie \& Thirlwall, 2016; Romer, 1986).

Models in the Keynesian approach explore the aspects of cumulative development, driven primarily by the positive economies of scale (the neoclassicists, in contrast, emphasized declining returns). According to the Keynesian approach, the manufacturing process (especially of high value-added products) by itself becomes a "flywheel" capable to stimulate innovations, generate productivity gains and drive further sustainable growth. Thus, it is emphasized that peripheral regions often fall into a trap of the "vicious circle of poverty".

A number of terms have been used in the economic literature for the denomination of gravity forces that lead to concentration or dispersion of economic activity. The difference between them is rather blurred. In particular, the most widespread are:

1. "Spread effects" and "backwash effects" (Myrdal, 1957), which describe the tendency of the core region to stimulate the periphery's development (being the main customer and market) or its decline (through the "pumping" of capital and labour).

2. "Trickling-down effects" and "polarization effects" (Hirschman, 1958), which in general terms are similar to the previous ones, but are used with an emphasis on socio-cultural "micro-causations" (the trickle-down effect emphasizes that the poorest members of society benefit from the welfare of the richest, while the polarization effect underlines the gap in welfare levels);

3. Spillover effects within the "core-periphery" models of Prebisch (1959) and Friedmann (1969), among which there are separated the sub-effects of dominance, information, psychology, production, communication etc.

4. The effects of the centripetal and centrifugal gravity forces by Krugman (1991), which are a formalized in the "New Economic Geography" model.

5. The effect of "polarization reversal" (Richardson, 1980) in attempting to synthesize neoclassical and Keynesian approaches, according to which polarization occurs until the certain critical moment, after which a reverse convergence process will be initiated.

6. The effect of "capital surplus absorption" in contemporary adaptations of Marxism ideas (Harvey, 2010).

Thus, in general, the current periphery paradigm lies on the conceptual platform of regional development models involving the technological, institutional and social arguments and their synthesis. As of today, it can be argued that regional progress is a combination of numerous endogenous and exogenous factors, and the prosperity or 
peripheralization of a region depends on both the spectrum of local activity and the interregional, national and global system.

\section{Review of the empirical researches on regional peripheralization}

There is much empirical evidence that densely populated areas are locations with higher levels of productivity (Glaeser \& Gottlieb, 2009; Rosenthal \& Strange, 2004), innovation and entrepreneurship (Acs, 2003; van Oort, 2017), creativity (Florida, 2002), human capital development (Berry \& Glaeser, 2005) and major centers of learning and research (Anselin, Varga, \& Acs, 1997). However, the above observations cannot be interpreted as an automatic indication that economic growth is restricted to urban areas only. It also does not mean that productivity gains are an indispensable feature of large cities that continue to grow. The situation is more complex and depends on large capital flows and activities of non-central regions, including those that were not particularly urbanized initially.

In this context, several tendencies marked by OECD should be noted. While acknowledging the uneven spread of economic growth and prosperity, OECD highlights two important features:

- the share of national and international economic growth for which large hubs of knowledge (so-called "city-regions") are responsible varies from 20 to $30 \%$ depending on the extent of spatial disaggregation. However, such a share is quite stable both from the perspective of the states and in the temporal dimension. Therefore, the share of other regions in economic growth is dominant and ranges between 70-80\%;

- currently, the most dynamically growing regions in most countries are not large urban hubs or even city regions, but other types of regions, some of which were traditionally recognized as lagging peripheries (OECD, 2018).

However, it should be emphasized that the mentioned OECD observation is only valid for the last decade. As early as the 1990s, urban regions were characterized by higher rates of economic growth than rural and intermediate regions. For the first time, the change in the pattern of regional growth in favour of non-central and peripheral regions was observed by Broersma \& Van Dijk (2007).

Today, many regions with lower absolute productivity are characterized by relatively higher levels of productivity growth and output. Thus, in 15 of the 30 OECD Member States, GDP per capita growth rates in $10 \%$ of the poorest regions were higher than in 10\% of the richest regions during 2011-2016. The long-term effect of such a transformation remains a debatable issue, especially in developing countries.

Therefore, the modern period of globalization is characterized by a comprehensive picture of economic geography, and the roles of successful and peripheral regions have evolved in different directions. The global city networks remain relevant as the centres of knowledge concentration, which is especially relevant for the service sector that is dependent on the exploitation of trust relations. Nevertheless, despite the persistence of inter-regional intra-state divergences (with a tendency towards inter-state convergence, at least among developed countries), 
agrarian, intermediate and non-central urban regions have become drivers of economic growth in recent years. However, in less developed countries, the role of central metropolises for growth remains crucial, as evidenced by the rapid increase in the international importance of cities such as Shanghai, Mumbai, Johannesburg, Jakarta, São Paulo etc.

Europe is an example of a mega-region, that consists of the mix of advanced and depressive territories (the latter could be distinguished into "inner periphery" and "border periphery" with their own specific features).

The areas of the inner periphery are characterized by the following possible expressions (or their combinations):

- enclaves with low economic potential, a manifestation of which is a considerable geographical distance from the centres of economic activity and which requires, first of all, the development of transport infrastructure and logistics system;

- areas with low access to public services that are more likely to require the latest ICT solutions, while restructuring of the administrative structure in order to stimulate the economies of scale may worsen the situation;

- areas experiencing a lack of relational proximity, in which attention should be paid to the development of interaction between local actors (ESPON, 2017).

The key to analyse the inner periphery is the ability of the territory to "reconcile" with its environment, which is determined not so much by "geography" but rather by relational non-spatial factors and processes. High-connected territories create better opportunities for development, better access to public services and a more dynamic workforce capable of retaining skilled labour. These benefits, in turn, generate opportunities for new connections and the initiation of new spiral turns of well-being.

The Fig. 1 reveals a map of European inner periphery according to ESPON, highlighting the main peripheral factors:

1. Areas for which the main factor is the poor economic and demographic situation ( $46 \%$ of the entire inner periphery);

2. Areas with insufficient access to services and/or regional centres (45\%);

3 . Areas for which both of the above factors (9\%) occur simultaneously. 


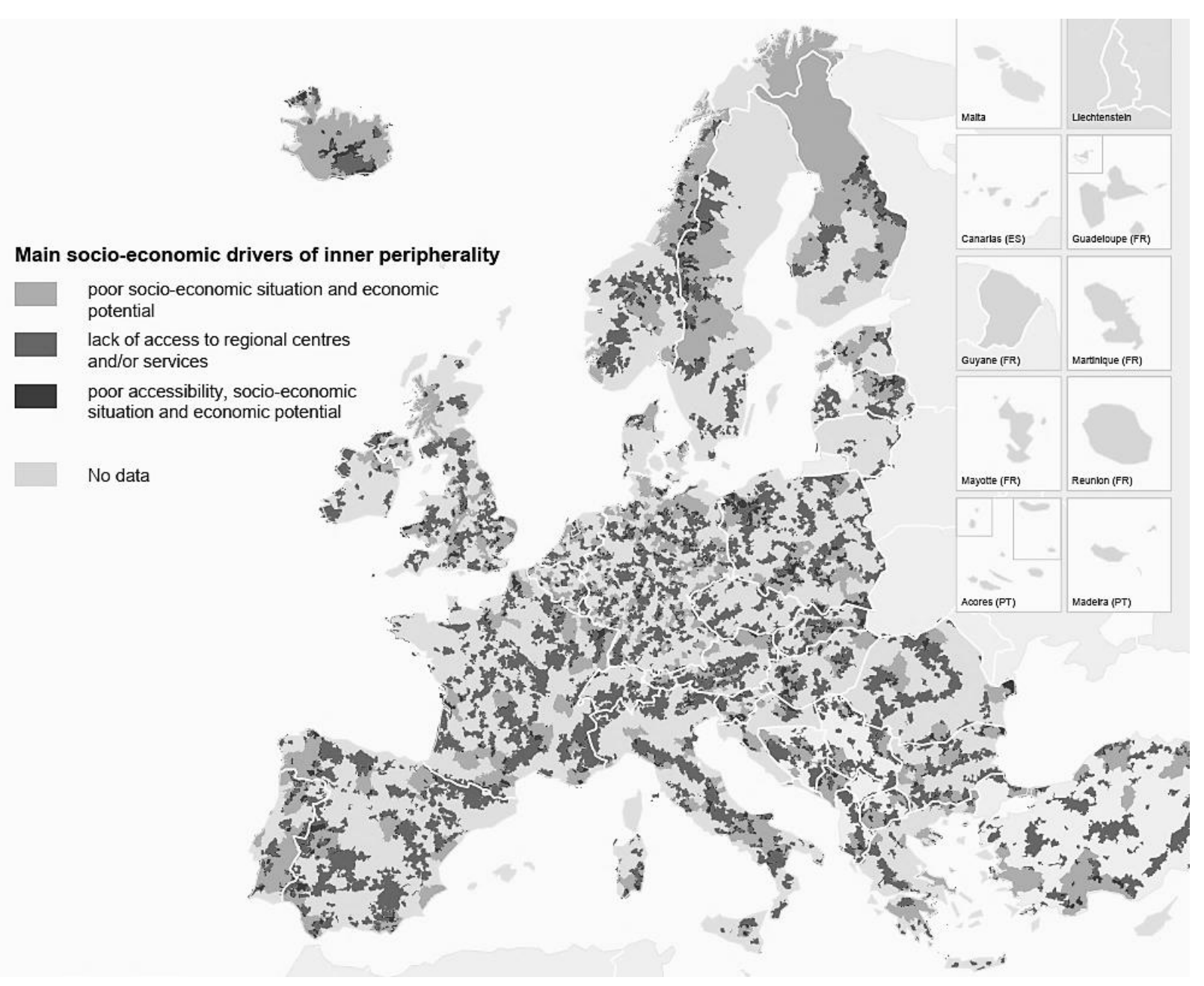

Fig. 1. Geographical distribution of inner periphery in Europe Source: (ESPON, 2017)

The map illustrates that peripheral regions are often geographically an internal periphery. In addition, border regions both in the national and interregional context are tended to be intra-peripheral.

$80 \%$ of the inner periphery with low economic potential or poor access is located in non-urbanized regions, spreading relatively evenly across rural and intermediate territories. It can also be noted that about half of the area of the inner periphery, characterized by poor access, falls into the mountainous area.

Areas for which there is a lack of relational proximity are located in urbanized (32.2\%) and metropolitan (43\%) territories more often than in the other two types of the inner periphery. Peripheral processes associated with poor socio-economic performance are also more likely to relate to "enclaves" of these territories.

\section{Methodology}

The analysis of the peripheralisation of the European regions will be carried out according to the parameters of population density, employment and the gross regional 
product. The database includes the NUTS- 2 regions of the EU member states, Norway and Macedonia for the period 2006-2016 according to Eurostat (sample consists of 3124 observations). Except for the general statistical characteristics of the dataset, we will calculate the coefficient of variation to show the percentage of standard deviation of the above-mentioned parameters to their mean (to find out the lag between advanced regions and peripheries). Besides, the coefficient of oscillation $(($ max.-min. $) /$ mean $)$ will be calculated to show the "peakiness" of dataset.

The results of the calculation will allow to compare the distribution of population, employment, production and their dynamics among European regions, and to indicate the peripheral regions according to these parameters. The map of average annual growth of employment and regional GDP will reveal the new European "poles". The analysis of the correlation between parameters and their dynamics will allow making conclusion whether European peripheral regions tend to remain poor or they narrow the gap with advanced regions.

\section{Results}

Table 1 (column 2) reveals the statistical characteristics of the sample of average population density indicators. The results confirm the high level of population disparity in Europe, with the largest concentration in specific regions of the United Kingdom, Belgium and Spain, and the least populated areas of the Scandinavian states. If we consider the situation in dynamics, the largest increases of average population density over the last decade was observed mainly in the higher density regions, which is an argument for the self-enhancing effect of the agglomeration. However, the relationship between population density and its growth is rather weak (the correlation coefficient was only 0.26). It is also worth highlighting the individual regions of France (Corsica) and Norway (Gedmark), which are in $10 \%$ of the least densely populated European regions but are characterized by very high population density growth (more than $1.1 \%$ year on year in 2006-2016).

Table 1. The pattern of population density and employment, NUTS-2, 2006-2016

\begin{tabular}{|l|c|c|}
\hline \multicolumn{1}{|c|}{ Indicator } & $\begin{array}{c}\text { Population density } \\
\left.\text { (people per } \mathrm{km}^{2}\right)\end{array}$ & $\begin{array}{c}\text { Employment } \\
\text { (thousand persons) }\end{array}$ \\
\hline \multicolumn{1}{|c|}{1} & 2 & 3 \\
\hline Average value & 445 & 783,7 \\
\hline Variation & 10193 & 5217,2 \\
\hline Standard deviation & 1172,1 & 642,3 \\
\hline The coefficient of variation & $263 \%$ & $82 \%$ \\
\hline The coefficient of oscillation & 22,9 & 6,65 \\
\hline
\end{tabular}

The high level of peakiness was also shown by the analysis of absolute data on the example of employment in the European regions for the same period (column 3 of the table), but the coefficients of variation and oscillation were though high, but lower than in the analysis of population density. The highest average increase in absolute employment rates (more than $2 \%$ on average per year) over the last decade has been typical for the regions of Poland (Greater Poland, West Pomeranian and Pomeranian 
Voivodeship), Great Britain (Internal and External London), Malta and Luxemburg. The most significant declines in employment $(-1.9 \%$ and below the average for the year) were observed in the territories of Romania (South-West and South-East Romania), Greece (8 regions) and Bulgaria (North-East region). Interestingly, the correlation between the absolute number of employees and its annual growth rate is not traced at all (correlation coefficient 0.02). The correlation coefficient between population density and the absolute employment rate was 0.47 .

European countries differ significantly concerning the distribution of employment depending on the level of urbanization. The pan-European trend is to reduce the relative weight of large cities in the overall employment structure (in 2017, the decrease in the relative weight of large cities in the EU countries averaged 4 percentage points compared to 2006). The states with the highest relative employment reductions in large cities are Malta (37 p.p.), Greece (29 p.p.), Belgium and Croatia (25 p.p.). Only 11 of the 31 states under consideration saw an increase in the relative employment rate in large cities (Sweden $+14 \mathrm{pp}$, Finland $+11 \mathrm{pp}$ ). Instead, the share of small cities, suburbs and villages in the employment structure is steadily increasing. The relative weight of small cities and suburbs: $+7 \mathrm{pp}$ for the EU and $+4 \mathrm{pp}$ for the euro area; villages: $+3 \mathrm{pp}$ for the $\mathrm{EU}$ and $+4 \mathrm{pp}$ for the euro area (the effects of monetary integration in the EU is considered in Lyzun et al. (2019).

The heterogeneity of the regions by economic criteria is also quite significant. Thus, in terms of regional GDP PPP (Table 2, column 2) the most advanced are the regions of France (Ile-de-France, Rhône-Alpes), Italy (Lombardy, Lazio, Piedmont), Spain (Catalonia, Madrid, Andalusia) and Germany (Upper Bavaria, Dusseldorf, Darmstadt, Stuttgart). Among the most depressed are some regions of Finland (Aland Islands), Spain (Ceuta, Melilla), Portugal (Azores), Greece (Northern Aegean, Ionian Islands, Western Macedonia, Epirus) and Italy (Valle d'Aosta). In the dynamics, most regions are characterized by a positive GDP growth over the last decade. Of the 7 regions with average annual GDP growth of more than 5\%, five were in Poland (Masovia, Greater Poland, Lower Silesia, Lesser Poland and Pomeranian Voivodeship) and one in Romania (Bucharest-Ilfov) and Ireland East of Ireland). Of the 16 regions with negative GDP growth, 13 were located in Greece and one in Spain (Asturias), Italy (Molise) and the Netherlands (Groningen).

Table 2. The pattern of regional GDP and GDP per capita, NUTS-2, 2006-2016

\begin{tabular}{|l|c|c|}
\hline \multicolumn{1}{|c|}{ Indicator } & $\begin{array}{c}\text { Regional GDP } \\
\text { (mln. PPP standards) }\end{array}$ & $\begin{array}{c}\text { GDP per capita } \\
\text { (PPP standards per 1 person) }\end{array}$ \\
\hline 1 & 2 & 3 \\
\hline Average value & 47731,8 & 1,3 \\
\hline Variation & 554038,8 & 12,4 \\
\hline Standard deviation & 53351,6 & 1,6 \\
\hline The coefficient of variation & $112 \%$ & $124 \%$ \\
\hline The coefficient of oscillation & 11,6 & 9,5 \\
\hline
\end{tabular}

A much lower level of sampling heterogeneity (estimated by the coefficient of variation) and its "peakiness" (estimated by the coefficient of oscillation) is observed 
in the analysis of GDP per capita (column 3). External London is the undisputed leader exceeding by almost three times the level of its closest competitor. The poorest regions are Bulgaria (all regions except Southwestern), Romania (Northeastern Romania) and Macedonia.

A visualization of the average annual employment growth and per capita GDP for the European regions of the NUTS-2 level in Fig. 2 shows a tendency to form new poles to the east of the traditional economic spine of Europe (the so-called "Blue Banana" - the region covering London, the Benelux countries, Bavaria, and Lombardy).

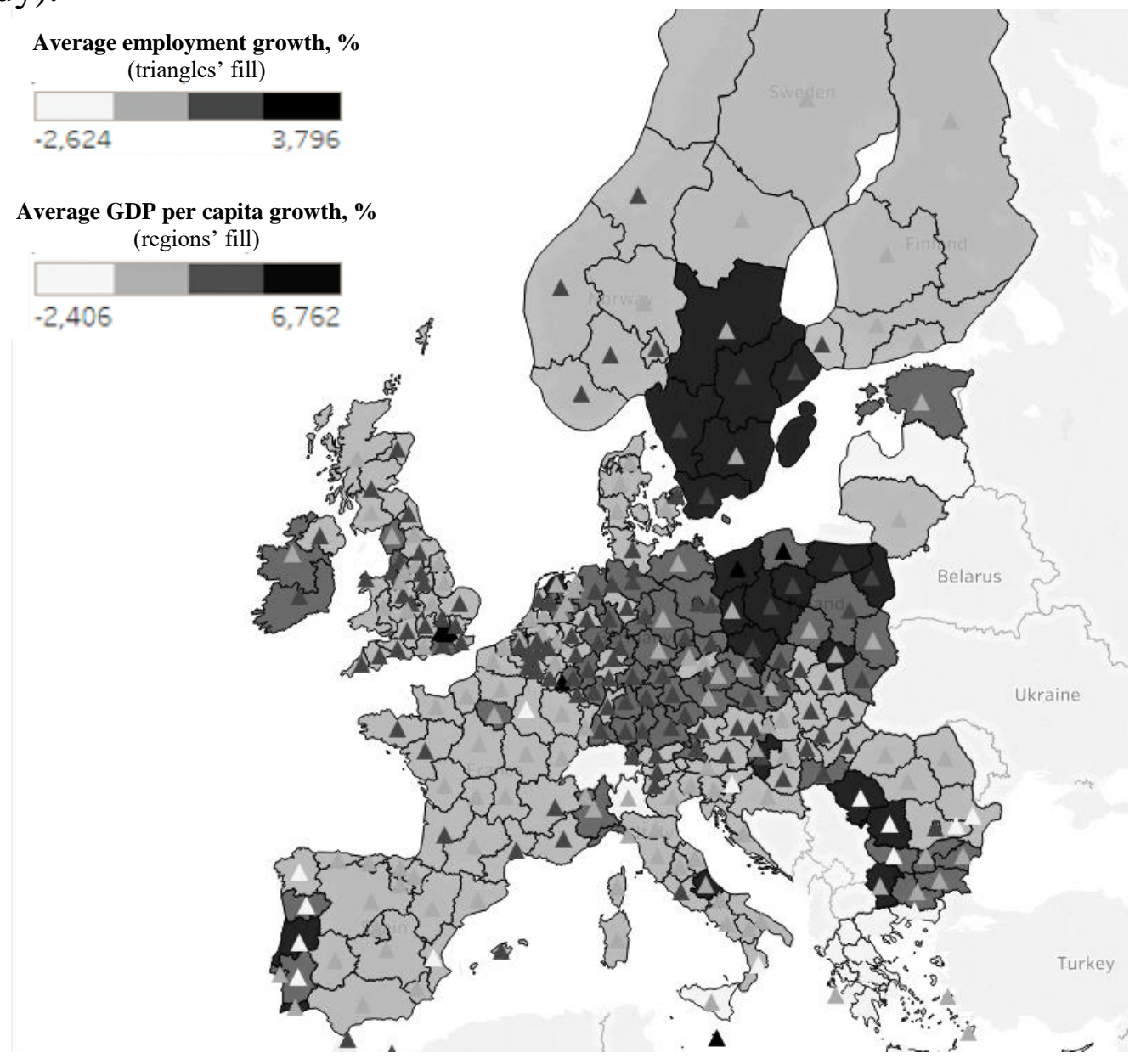

Fig. 2. Growth poles in terms of dynamics of employment and GDP per capita Source: authors using Eurostat data and Tableau 2019.1 tools

By examining the correlation coefficients between the considered parameters of the European regions, a very strong linear correlation (the correlation coefficient equals 0.92) can be found between the average employment and the average GDP. It is also worth pointing out a fairly strong proportional relationship between population density and per capita GDP (the correlation coefficient equals 0.51). 


\section{Conclusions}

Summarizing aspects of territorial disparities, it can be noted that in reality new layers of inequalities are imposed on previously inherited spatial structures". This historical "legacy" of local and regional economic development is also reflected in globalization processes. Imposing different effects can lead to increased inter-regional convergence and divergence, depending on which new industries are developing and which regions will choose firms to make new investments. In other words, the final results of changes in individual regions or countries depend on the sectoral and spatial structures and their history, the experience of neighbouring regions and countries, and the actual scale of local technological change. The ultimate balance of the factors of spatial convergence and divergence is, after all, confirmed in the empirical models but is difficult to predict with a sufficient level of confidence in theoretical models.

Considering the progress of European periphery during the latest decade we should admit first of all the leap of Visegrad Group countries (Poland, Czechia, Slovakia and Hungary), where regions established the new growth pattern - so-called "Eastern European Boomerang" that could counterbalance the traditional "Blue Banana" of Old Europe. However, the declining dynamics is observed in European South (first of all in Greece), thus the peripheral tendencies in Europe are rather twofold.

\section{Acknowledgements}

This work was supported by the Erasmus+ program of the European Union (Jean Monnet Module 612067-EPP-1-UA-EPPJMO-MODULE "European Regional Policy: Balance of Local, National and Pan-European Interests"). The European Commission support for the publication of this article does not constitute an endorsement of the contents, which reflects the views of the authors only, and the Commission cannot be held responsible for any use, which may be made of the information contained therein.

\section{References}

Acs, Z. J. (2003). Innovation and the Growth of Cities. - Edward Elgar Publishing. 247 p.

Anselin, L., Varga, A., Acs, Z. (1997). Local geographic spillovers between university research and high technology innovations // Journal of Urban Economics, Vol. 42(3): 422-448.

Berry, C. R., Glaeser, E. L. (2005). The divergence of human capital levels across cities // Papers in Regional Science, No. 84(3): 407-444.

Broersma, L., Van Dijk, J. (2007). The effect of congestion and agglomeration on multifactor productivity growth in Dutch regions // Journal of Economic Geography. No. 8(2): 181-209.

ESPON (2017). Inner peripheries in Europe - Possible development strategies to overcome their marginalising effects. - https://www.espon.eu/inner-peripheries-brief [2019.05.06]

Florida, R. (2002). The rise of the creative class. - New York: Basic books. 512 p.

Friedmann, J. (1969). The future of urbanization in Latin America: Some observations on the role of the periphery // Papers in Regional Science. No. 23(1): 161-176. 
Glaeser, E. L., Gottlieb, J. D. (2009). The Wealth of Cities: Agglomeration Economies and Spatial Equilibrium in the United States // Journal of Economic Literature. No. 47(4): 983-1028.

Harvey, D. (2010). The right to the city: From capital surplus to accumulation by dispossession. - SAGES. p. 17-32.

Hirschman, A. O. (1958). The strategy of economic development. - New Haven: Yale University. $217 \mathrm{p}$.

Krugman, P. (1991). Increasing returns and economic geography // Journal of Political Economy, No. 99(3): 483-499.

Lyzun, M., Lishchynskyy, I. (2018). Social efficiency of the Economic and Monetary Union // Scientific Bulletin of Polissia. Vol. 13, No. 1: 184-188.

Lyzun, M., Lishchynskyy, I., Savelyev, Y., Kuryliak, V. and Kurylyak, Y. (2019). Modeling Evaluation of Dollarization Economic Efficiency. International Conference on Advanced Computer Information Technologies (ACIT). Ceske Budejovice, Czech Republic: 366-370.

Lucas, R. E. (1988). On the mechanics of economic development // Journal of Monetary Economics, No. 22(1): 3-42.

McCann, P. (2013). Modern Urban and Regional Economics. - Oxford: University Press, $408 \mathrm{p}$.

McCombie, J., Thirlwall, A. P. (2016). Economic growth and the balance-of-payments constraint. - Springer. $616 \mathrm{p}$. $175 \mathrm{p}$.

Myrdal, G. (1957). Economic theory and underdeveloped regions. - Gerald Duckworth.

OECD (2018). Regions and Cities at a Glance 2018. - https://www.oecd-ilibrary.org/ governance/oecd-regions-and-cities-at-a-glance-2018_reg_cit_glance-2018-en [2019.09.25]

Prebisch, R. (1959). Commercial policy in the underdeveloped countries // The American Economic Review. No. 49(2): 251-273.

Richardson, H. W. (1980). Polarization reversal in developing countries // Papers in Regional Science. No. 45(1): 67-85.

Romer, P. M. (1986). Increasing returns and long-run growth // Journal of Political Economy. No. 94(5): 1002-1037.

Rosenthal, S. S., Strange, W. C. (2004). Evidence on the Nature and Sources of Agglomeration Economies. In J. V. Henderson \& J.-F. Thisse (Eds.), Handbook of Regional and Urban Economics. - Elsevier. p. 2119-2171.

Van Oort, F. G. (2017). Urban Growth and Innovation: Spatially Bounded Externalities in the Netherlands. - Routledge. 285 p.

Warf, B. (1995). Telecommunications and the Changing Geographies of Knowledge Transmission in the Late 20th Century // Urban Studies, No. 32(2): 361-378. 